\title{
PPs without Disguises: Reply to Bruening
}

\author{
Javier Ormazabal \\ Juan Romero
}

Bresnan and Nikitina (2009) and Rappaport Hovav and Levin (2008) show that, contrary to standard assumptions, fixed-theme idioms may appear in to-constructions under certain pragmatic circumstances. Bruening (2010a) contends that the cases they present are in fact $\mathrm{R}$ (ightward)-dative shifts, double object constructions with the object projected to the right. In this article, we argue that Bruening's proposed theoretical apparatus is unnecessarily complex and ad hoc and falls short of explaining the main facts it is supposed to deal with, massively overgenerating. A regular PP structure is argued to be empirically more adequate and conceptually simpler, avoiding the main problems of the R-dative shift analysis. New empirical evidence concerning pairlist readings and scope freezing also suggests that the empirical facts about idioms should be reconsidered in completely different terms.

Keywords: idioms, double object constructions, scope asymmetries, frozen scope, dative alternations

\section{R(ightward)-Dative Shift}

It has been standard in the literature to assume that fixed-theme idioms of the type in (1) only appear in double object constructions (DOCs) and do not allow the to-construction (see Green 1974, Harley 2002, Krifka 2004, and references there). However, Bresnan and Nikitina (B\&N) (2009) report many examples of the type in (2), gathered from different sources, that seem to contradict this claim (also see Snyder 2003, Rappaport Hovav and Levin (RH\&L) 2008).

(1) lend (somebody) an ear, promise (somebody) the moon, give (somebody) the creeps, give (somebody) a headache, give (somebody) a punch, etc.

The two authors, listed in alphabetical order, are equally responsible for the entire content of the article. We are very thankful to Myriam Uribe-Etxebarria and to Bryan Leferman and Ruth Yates, whose comments were particularly helpful in understanding some of the data discussed in section 4.

This work was financially supported in part by the institutions supporting the research activities of the Group of Theoretical Linguistics (HiTT): the Basque government's grant GIC07/144-IT-210-07 (Euskal Unibertsitate Sistemako Ikerketa-taldeak), the Spanish government's Ministry of Science and Development grants FFI2008-04786 and FFI201129218, the Basque government's Gai espezifikoetarako ikerketa-taldeak finkatzeko laguntzak 2008 (project Sobre la construcción e interpretación de las estructuras lingüísticas ref.: HM2008-1-10) and 2009 (project Universal Grammar and Linguistic Variation), and the University of the Basque Country's (UPV/EHU) UFI-11/14. 
(2) a. ... a stench or smell is diffused over the ship that would give a headache to the most athletic constitution.

(B\&N 2009:(12))

b. ... she gave a punch to the evil reporter that had asked the dumb ass question.

(B\&N 2009:(13))

Bruening (2010a) acknowledges that many of B\&N's examples are acceptable, but he contends that they do not correspond to to-constructions; rather, he proposes that they correspond to a DOC in disguise, concluding that polysemic approaches to dative alternations are superior to derivational ones. To see his argument, consider the minimal triplet in (3), based on Bruening's examples $(2 \mathrm{a}-\mathrm{b})$ and $(14 \mathrm{~d})$ and minimally modified for the sake of the discussion. ${ }^{1}$

(3) a. The lighting here gives me a headache.

b. *The lighting here gives a headache to me.

c. The lighting here gives a headache to everyone who enters the room.

According to Bruening, the two structures in $(3 b-c)$ look identical on the surface but have different derivations. While the ungrammatical (3b) is a to-construction involving a small clause $\mathrm{PP}$, as in (4), the grammatical (3c) corresponds to a DOC where the first object is projected to the right - an R-dative shift (rightward dative shift) in Bruening's terminology - and then moves further rightward to adjoin to a higher projection, via heavy NP extraposition, as in (5) (see Bruening's structures (7) and (10)).

(4)

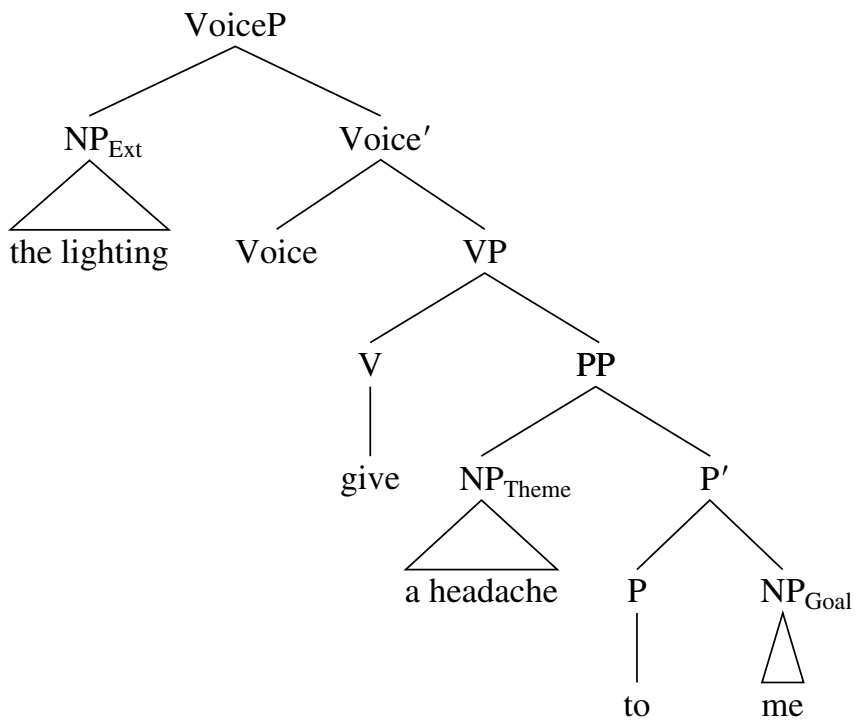

\footnotetext{
${ }^{1}$ We will come back to the grammatical status of example (3b) at the end of section 2 .
} 
(5)

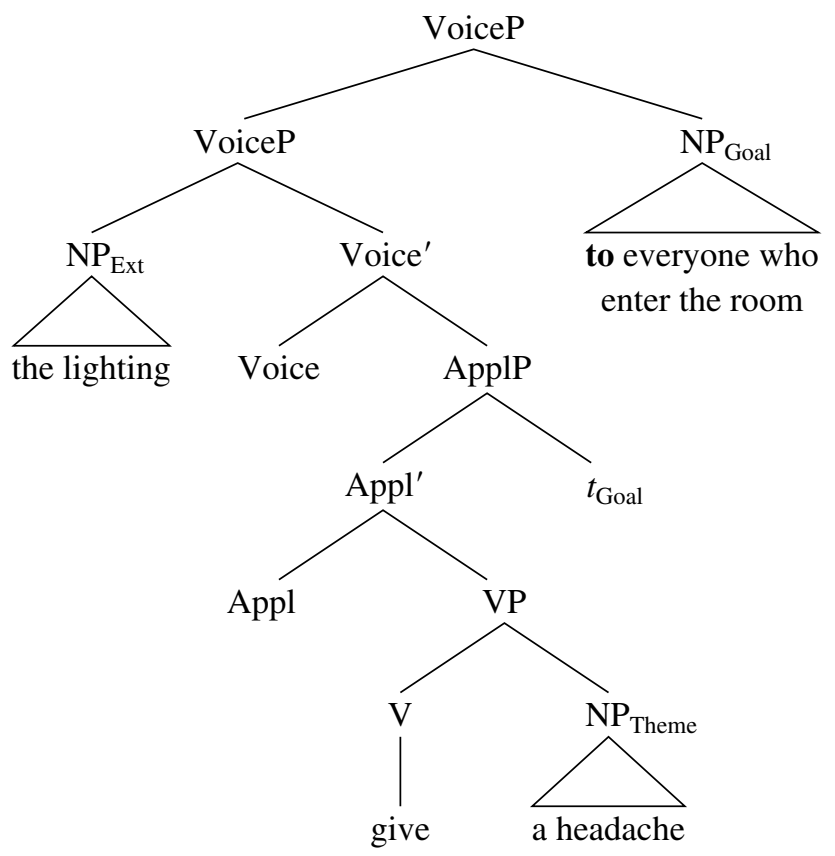

Bruening's analysis would make it possible to save a central argument in polysemic analyses against a derivational account of the dative alternation: that the lack of the to-construction in fixed-goal idioms leaves the DOC without a source from which it could be syntactically derived. The main empirical motivation for R-dative shift is its alleged capacity to accommodate some interesting scope asymmetries and locative inversion facts in idiomatic contexts. Consider the paradigm in (6), selected from Bruening's examples (13)-(14). Bruening observes that as in DOCs, (6a), fixed-theme idioms with to-complements do not allow wide scope of every in the theme position, (6b), contrasting somewhat surprisingly with regular to-constructions, (6c).

(6) a. This lighting gives a different person every kind of headache. (*every $>$ a)

b. This lighting gives every kind of headache to a different (type of) person. (*every $>$ a)

c. I gave every candy bar to a different child. (every $>$ a)

(Bruening 2010:294, (14b-c); 293, (13a))

To account for these facts, Bruening appeals to the idea that the goal argument occupies a higher position in an applicative projection. In the structure in (5), the goal "asymmetrically c-commands the theme NP. The goal NP will therefore always move first in any scope-taking movement, given standard locality constraints on movement, and it will be impossible for the theme NP to cross over the goal', (p. 293).

In his article, Bruening explores additional consequences of his proposal regarding the availability of certain pair-list readings with idioms, wh-movement, and weak crossover. He also 
presents the behavior of idioms with respect to locative inversion as a strong argument for his position; however, we believe this last argument to be invalid. Bruening shows that fixed-theme idioms allowing to-complements of the type discussed by $\mathrm{B} \& \mathrm{~N}$ do not accept locative inversion, minimally contrasting in that respect with regular to-constructions, as the paradigm in (7) shows. (7a) is a case of locative inversion in a passive construction with a nonidiomatic VP; the ungrammatical (7b) minimally differs from (7a) in that give hell is an idiomatic expression. Locative inversion is thus possible with genuine to-constructions, but not with R-shifted datives. (7c) completes the picture by showing that the first object of a DOC in a fixed-theme idiom can passivize in the regular way. In consequence, Bruening concludes that the contrast in $(7 b-c)$ shows that the R-dative shift construction is different from the to-construction.

(7) a. To the generals that lost the battle were given helicopters.

b. *To the generals that lost the battle were/was given hell.

c. The generals that lost the battle were given hell.

(Bruening 2010a:297, (27))

However, it is a general observation in the literature on locative inversion (e.g., Bresnan and Kanerva 1989, Bresnan 1994, and references cited there) that transitive sentences allow locative inversion only if the construction is passivized. Bruening's example (7c) shows that these idioms allow passivization, but in the DOC, where the passivized argument is the goal in "first object", position. In contrast, the base structure for locative inversion in (7b) is not (7c) but the ungrammatical (8).

(8) *Hell was given to the generals that lost the battle.

In fact, in a different article, Bruening (2010b) himself observes that in contrast to (7c), this kind of idiom disallows passivization of the theme/patient in the to-construction (examples given by Bruening (2010b:539, (39)), who adds the comment "no examples found using Google" to all of them).

(9) a. *The creeps were given to him.

b. *A piece of your mind should be given to him.

c. *A headache will be given to anyone who enters this room.

d. *The boot was given to him.

e. *The sack was given to him.

f. *The moon was promised to him.

The same conclusion holds of the rest of the idioms and nonalternating verbs involving locative inversion mentioned in Bruening's (2010a:sec. 3) discussion.

(10) a. *A good scrubbing was given to the tables.

b. \#A horrible headache is given to anyone who stays too long in this room.

c. *Some of the rights were denied to minorities. 
Given that locative inversion requires passivization, the origin of the ungrammaticality is not locative inversion itself, but the unavailability of the passive source that makes it possible. The asymmetry presented by Bruening with respect to passivization in fixed-theme idioms is a very interesting one, and a deep analysis of its properties and limits might shed some light on the interaction between idioms and dative constructions, ${ }^{2}$ but the lack of the passive source in toconstructions makes the locative inversion irrelevant to decide the structural properties of these constructions. As a consequence, we will not deal with these facts here.

In this article, we argue that Bruening's proposal is theoretically and empirically inadequate and does not explain some of the facts it is supposed to deal with. In section 2, we argue that the proposed theoretical apparatus is unnecessarily complex and ad hoc, and that it overgenerates-contradicting well-established structural properties associated with the constructions involved in dative alternations. In that vein, we show that a regular PP analysis deals with the relevant cases and does not have the same overgeneration problem; Bruening's R-dative shift and Extraction Constraint on Rightward Specifiers (see below) are therefore not needed to account for the data. In section 3, we argue that empirical and theoretical consideration of certain $w h$ movement and weak crossover facts clearly supports an analysis where the goal is base-generated as a PP. In section 4, we show that the empirical facts concerning pair-list readings and scopefreezing phenomena with idiomatic expressions are considerably more complex than pictured in Bruening 2010a and also extend to contexts where an R-dative shift analysis is not an option.

\section{Conceptual and Theoretical Considerations}

\subsection{A Complex Apparatus}

Bruening's proposal represented in (5) has two characteristic properties that deserve special attention. To begin with, in order to rule out cases like (3b), Bruening must restrict the possibility of rightward projection in the DOC to cases where the first object is additionally moved to an $\bar{A}$-position-either by wh-movement, by heavy XP shift, or by extraposition. More generally, this restriction is needed so that the system does not do away with the difference between DOCs and PP constructions altogether. In Bruening's system, this restriction is formulated as the constraint in (11).

(11) The Extraction Constraint on Rightward Specifiers

The specifier of ApplP may be ordered to the right of its sister only if the NP that occupies it undergoes $\bar{A}$-extraction.

(Bruening 2010a:291, (9))

\footnotetext{
${ }^{2}$ Bruening (2010b:537) suggests that "whether an idiom alternates or not is just going to be a property of that particular idiom, with little to say about the syntax of ditransitives generally." It seems to us that something more interesting can be said about this asymmetry; but if Bruening's suggestion is right, then neither locative inversion nor the asymmetries in passivization would be of much real importance for the theoretical discussion.
} 
It is not obvious that (11) does any work in the system other than stipulate the contexts where to-constructions may appear with fixed-goal idioms. We are thus confronted with a general condition whose scope reduces to constraining by pure force the cases where under polysemic approaches there should be no alternation.

Furthermore, although Bruening's system is designed specifically to restrict the scope of the $R$-dative shift construction, it overgenerates massively. As Bruening himself observes, given (11), for any to-construction subject to $\bar{A}$-movement there are two possible analyses. Thus, (12) is analyzed as corresponding to two different derivations: one in which the sentence is generated as a regular to-construction, and one involving an extraposed R-dative shift construction.

(12) I give candy to anyone who offers me a seat on the bus.

(Bruening 2010a:292, (11))

However, this analysis would predict that to-constructions should be ambiguous with respect to Barss and Lasnik's (1986) structural asymmetries-a prediction that is not borne out. To see this point, consider the following examples, from Larson 1988:338 (some of them slightly modified to make the to-construction heavier and allow heavy XP shift to apply more easily).

(13) a. I presented/showed Mary to herself. (anaphor binding)

*I presented/showed herself to anyone who offered me a seat on the bus.

b. I gave/sent every check $_{\mathrm{i}}$ to its $_{\mathrm{i}}$ owner. (quantifier binding) ??I gave/sent his ${ }_{i}$ paycheck to every worker $_{i}$ that came to the office on Friday.

c. Which check $_{\mathrm{i}}$ did you send to its $\mathrm{i}_{\mathrm{i}}$ owner?

(weak crossover) *Which worker $_{\mathrm{i}}$ did you send his $\mathrm{s}_{\mathrm{i}}$ check to?

(superiority)

d. Which check did you send to who?

*Whom did you send which check to?

e. I sent each boy to the other's parents.

(each... the other)

*I sent the other's check to each boy that participated in the meeting.

f. I sent no presents to any of the children.

*I sent any of the packages to none of the children who were at the party.

Following Bruening's reasoning, all the ungrammatical examples in (13) would have a derivation where the to-construction is generated as an R-shifted dative and $\bar{A}$-moved higher in the structure via heavy XP shift or wh-movement. Since the dative is, by Bruening's hypothesis, generated structurally higher than the direct object, the anaphor herself in (13a), the variable it in (13b), the other in (13e), and the negative polarity item any in (13f) are bound by their respective antecedents, and the sentences should be grammatical. Similarly, extraction of the wh-phrase in 
$(13 \mathrm{c}-\mathrm{d})$ would be incorrectly predicted to not violate Superiority or Weak Crossover. As we will discuss in section 3, even if a plausible way could be found to restrict the R-dative shift analysis to constructions involving idiomatic expressions, the problem would persist.

Notice finally that Bruening's system needs some additional mechanism that "assigns" the preposition to to the right-adjoined NP in the R-dative shift construction in the absence of a prepositional element, while maintaining the "nominal" status of the first object in the R-dative shift construction. Bruening justifies the presence of to as a marker-possibly a Case markerthat phonologically distinguishes the first object from the theme, and he observes that this idea can be implemented technically in different ways (see his footnote 5). However, as RH\&L (2008: 153) observe - in response to a somewhat similar analysis proposed by Harley (2002) — this would be the only known case of heavy NP shift that requires the insertion of a preposition. ${ }^{3}$

It is worth remembering that the result of this complex apparatus is a surface structure that looks like a PP construction in terms of both order and constituents, but with the structure of a DOC. Given the complexity of Bruening's proposal, it is reasonable to ask whether the derivation he postulates is independently justified on empirical grounds over a simpler and more natural toconstruction analysis.

However, as we argue in the next section, the empirical facts at the core of Bruening's proposal do not support such a complex system, either. As we show, the scope asymmetries he presents obtain independently of whether the goal is generated as the first object of a DOC or as the complement of to, as long as the to-phrase raises to an extraposed position in the relevant context - an assumption independently needed in Bruening's analysis.

\subsection{A Simple/Regular to-PP Analysis}

Given the Extraction Constraint on Rightward Specifiers in (11) - tightly associated with dative shift - those structures where the to-DP is extraposed, and only those structures, will show reverse scope under Bruening's proposal. According to Bruening's rationale, this accounts for the basic empirical facts concerning quantifier scope interactions and locative inversion in (6)-(7).

However, a derivation where the to-goal is generated lower in a standard PP construction and then extraposes to a higher position would equally result in a structure where the PP c-commands the theme. Consider, for instance, the structure in (14), which combines Bruening's proposal for to-constructions in (4) with his characterization of heavy XP shift in (5).

\footnotetext{
${ }^{3}$ Although framed in very different ways, Emonds and Whitney 2006 and Ormazabal and Romero 2011 discuss numerous arguments supporting the claim that dative constructions-including English DOCs-involve the presence of a prepositional element (see the works cited and references given there).
} 
(14)

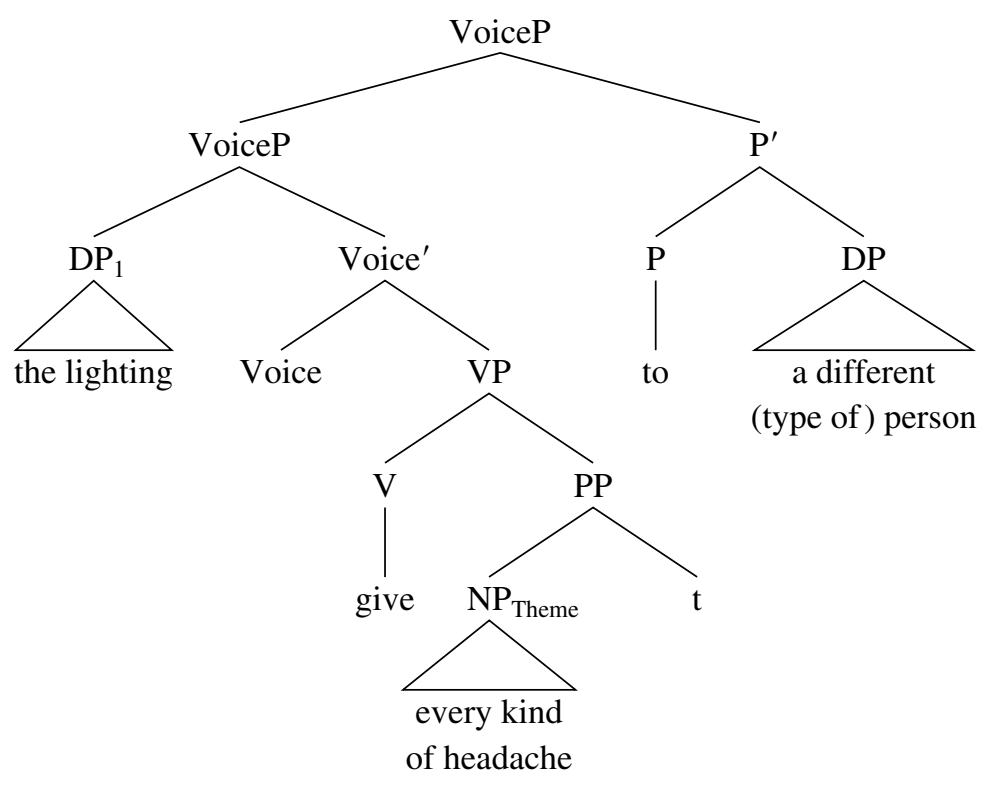

The extraposition operation in (14), which reverses the scope relations between every kind of headache and a different (type of) person in (6b), repeated in (15a), is independently needed in Bruening's analysis of R-dative shift.

(15) a. This lighting gives every kind of headache to a different (type of) person. (*every $>$ a)

b. I gave every candy bar to a different child. (every $>$ a)

Citing the behavior of spray-load verbs, Bruening claims that heavy XP shift does not alter scope relations. If that were correct, the movement of the $\mathrm{P}^{\prime}$ constituent in (14) would not affect the scope relations, and this derivation would not count as an alternative to account for the contrast in (15). However, the evidence Bruening presents does not support his claim. Consider the paradigm in (16), selected from Bruening's examples (20)-(27).

(16) a. I presented a different medal to every track and field athlete. (every $>$ a)

b. I presented a different track and field athlete with every medal. (*every $>$ a)

c. I presented with every medal a different track and field athlete. (*every $>$ a) (Bruening 2010a:295, (19a), (20a); 296, (21a))

The impossibility of inverse scope in (16b), as compared with (16a), suggests that a different track and field athlete is structurally higher than the with-complement, as already observed by Larson (1990) and Bruening (2001). Provided that this is correct, the only thing that (16c) shows is that when this argument is extraposed to an even higher position via heavy XP shift, inverse scope remains unavailable. But since the argument moves from a position already c-commanding 
the PP and does not cross over it, there is no reason why we should expect the scope relations to be altered by the extraposition operation. In consequence, the example does not say much about whether heavy XP shift affects scope relations or not. In the absence of empirical evidence to support that claim, the existence of a specific type of $\bar{A}$-movement that does not alter the scope relations in quantified expressions would be unexpected in Bruening's (2001) general proposal; some additional mechanism would need to be added to the system, reducing the generality of the hypothesis.

Assuming that such a mechanism does not form part of Universal Grammar, the scope interaction facts discussed by Bruening follow straightforwardly from the alternative analysis in (14). The extraposed PP asymmetrically c-commands the theme NP, and therefore it will be impossible for the latter to cross over the former. The frozen $a>$ every result in (6) is then obtained independently of whether the PP originates as the first object of a DOC or as the goal of a to-construction. ${ }^{4}$

An important empirical difference between Bruening's proposal and the PP-extraposition analysis in (14) is related to the contrast in (3), repeated in (17).

(17) a. The lighting here gives me a headache.

b. *The lighting here gives a headache to me.

c. The lighting here gives a headache to everyone who enters the room.

Bruening's explanation for the ungrammaticality of (17b) requires that two different derivations be ruled out. On the one hand, R-dative shift violates the Extraction Constraint on Rightward Specifiers in (11) because the goal in (17b) is too light to undergo $\bar{A}$-movement via heavy XP extraposition. On the other hand, the alternative PP structure is not possible because, crucially, Bruening assumes that the idiomatic interpretation is not allowed in the to-construction, in accordance with standard polysemic analyses of the phenomenon. In fact, the main point of Bruening's article is to argue that that conclusion is correct despite the existence of examples like (17c) and consequently that the polysemic approach is the only possible one. However, contrary to this assumption, the discussion in B\&N 2009 and in RH\&L 2008 (see especially the detailed discussion in RH\&L 2008:sec. 7 and references cited there) strongly suggests that the awkwardness of a sentence like (17b) is not syntactically or semantically driven, but related to the organization of the information structure of the sentence. In support of this claim, RH\&L discuss the paradigm

\footnotetext{
${ }^{4}$ In section 4, we argue that an extraposition analysis is not adequate to deal with scope interactions, either in Bruening's version or in the alternative (14), mainly for two reasons: (a) B\&N (2009) and RH\&L (2008) report many acceptable cases of fixed-goal idioms with to that do not involve heavy XP shift, and (b) once a broader set of contexts is considered, the scope interaction and pair-list reading facts in idiomatic expressions do not behave exactly as Bruening depicts them, and they require a radically different approach. However, for the sake of the discussion, in this section we continue to assume with Bruening that the to-phrase undergoes heavy XP extraposition. What is important for our account is to show that a unified PP analysis of to-complements deals better with the core empirical facts than the R-dative shift analysis and is much simpler theoretically.
} 
in (18) — parallel to the minimal pair under discussion - and argue that (18b) is unacceptable because in a default information structure supplied by the hearer, when no previous context is provided, the result is infelicitous. In fact, as RH\&L observe, when the right context is provided, as in (19), the to-construction becomes acceptable.

(18) a. Nixon's behavior gave Mailer an idea for a book.

b. \#Nixon's behavior gave an idea for a book to Mailer.

c. Nixon's behavior gave an idea for a book to every journalist living in NY City in the 1970 s.

(Snyder 2003:35, (48), as cited in RH\&L 2008:151, (51c))

(19) A: It is very difficult to get an idea for a book simply from an interview.

B: Well, interviewing Nixon gave an idea for a book to Mailer.

(RH\&L 2008:157, (66))

Similarly, in the case of fixed-theme idioms like (17b), the fixed chunks of the idioms are not referential (for discussion, see RH\&L 2008:sec. 7, and section 4 below). Consequently, they do not qualify as given information and tend to appear at the end of the sentence. This tendency may be overridden by other information-structural considerations, as in (17c) and (18c) where the recipient is heavy enough, in which case it also tends to appear at the right periphery of the sentence. $^{5}$

Given the discussion so far, no R-dative shift or Extraction Constraint on Rightward Specifiers seems to be required to deal with the scope asymmetries observed by Bruening. Consequently, since the main empirical evidence he presents is neutral with respect to the two analyses, Occam's razor favors a more parsimonious to-construction analysis over the more complex and ad hoc Rdative shift proposal. As we show next, putting the grammaticality status of (17b) aside, there is independent empirical evidence that supports a PP analysis over Bruening's.

\section{Overt Wh-Movement}

A clear indication that fixed themes in idiomatic constructions are base-generated in regular PP positions comes from the behavior of $w h$-movement and weak crossover, also discussed by Bruen-

\footnotetext{
${ }^{5}$ We conducted a Google search comparing the string lend an ear to me with the string lend me an ear, and although the DOC version was, as expected, overwhelmingly more common — in approximately a one-to-ten proportion-the to version was also widely attested.

It is also worth observing that many of the cases that B\&N (2009) and RH\&L (2008) discuss do not seem to involve extraposition of any kind, as the latter authors explicitly observe; see for instance (i), their (52c).

(i) You could give a headache to a Tylenol.

Incidentally, (i) is also interesting for a different reason: the goal is inanimate and therefore cannot appear as primary object in a DOC (for discussion, see Ormazabal and Romero 2007, 2011, and references there). Despite that fact, the sentence has an idiomatic reading in the to-construction, contrary to what polysemic approaches would predict.
} 
ing. As we will show, wh-movement provides strong theoretical and empirical evidence that the R-dative shift analysis is not needed.

\subsection{Extraction of the Goal}

It has been widely observed in the literature that many speakers of English do not allow the goal in a DOC to be extracted. Thus, for these speakers (20a) is ungrammatical. (The parenthesized asterisk in these examples indicates dialectal differences.) It is important to keep in mind that for the same speakers, extraction of the goal NP from the PP construction as in (20b), leaving to stranded, is perfectly acceptable.

(20) a. (*)Who did you give a book?

b. Who did you give a book to ?

Interestingly, Bruening observes that in fixed-theme idioms of the type discussed so far, these speakers still reject extraction of the goal in DOCs, (21a), but have no problem allowing it in the to-PP version, (21b), again leaving to stranded.

(21) a. (*)Who does he give the creeps?

b. Who does he give the creeps to ?

The exact correspondence between (20) and (21) — concerning both speakers' variability and the morphosyntactic shape of the goal argument-comes as no surprise in an analysis of (21b) where extraction of the goal in the idiom takes place from a regular to-phrase, exactly as in (20b).

Instead, Bruening interprets these facts as indicating that "[f]or many speakers . . , extraction of the goal NP in the double object construction is ungrammatical, unless the goal NP is shifted to the right and to appears"' (p. 296; italics ours). That is, speakers who disallow extraction of the first object in the DOC, (20a) and (21a), make an absolute exception when the first object is extracted from an R-dative shift, undermining Bruening's central claim that R-dative shift is the same syntactic object as the DOC in all relevant respects with the sole particularity that its specifier projects to the right. If the only difference in the derivations of (21a) and (21b) in Bruening's proposal is the linearization of the first object within ApplP, the systematic difference in grammaticality not only remains unexplained but in fact is unexpected under his own assumptions. ${ }^{6}$

Furthermore, the two analyses make different predictions regarding the Barss and Lasnik (1986) asymmetries illustrated in (13). Consider, for instance, superiority effects. If Bruening's proposed analysis for (21b) were correct, it would lead to these predictions: on the one hand, no

\footnotetext{
${ }^{6}$ Marantz (1993) observes that crosslinguistically, $\bar{A}$-extraction of the goal in DOCs is barred in certain languages (asymmetric object languages) and allowed in others (symmetric ones). As far as we know, this split is not overcome by any repair strategy such as Bruening's. In those asymmetric object languages with applicative morphology, extraction of the goal is not compatible with an overt applicative morpheme. Given the conceptual issue raised in the text, the lack of crosslinguistic empirical evidence constitutes an additional obstacle for Bruening's hypothesis.
} 
superiority effects would show up when the to-phrase moves, leaving the theme object behind; on the other hand, a wh-object would cross over the R-shifted dative, violating Superiority. In contrast, a PP analysis of the extraction in (21b) makes exactly the opposite predictions. Given the contrast in (22), the evidence supports the PP analysis.

(22) a. *Who did the lighting here give which headache to?

b. Which (kind of) headache did the lighting here give to whom?

The same conclusions can be extended to the other structural asymmetries illustrated in (13). In a nutshell, Bruening's proposal allows two different derivations for many to-constructions, derivations in which the theme and the goal exhibit opposite c-command relations in the base; this creates a general problem of overgeneration. Instead, a unified PP analysis of to-constructions reduces the basic c-command relations between the two arguments precisely in the direction suggested by Barss and Lasnik's asymmetries, since the theme is systematically generated in a position higher than the goal and locally binds it. Bruening proposes two alternative ways to make WCO and variable binding coherent with the R-dative shift analysis; however, as we will show in the next section, this solution cannot be right.

\subsection{Weak Crossover and Variable Binding}

We agree with Bruening that wh-movement takes place from the argument's A-position and cannot take place from a dislocated position, including the landing site of a shifted heavy XP. As Bruening observes, wh-extraction is possible only from a position to the left of temporal adjuncts, (23)-(24), although that fact does not say much about whether that position is an $\mathrm{R}$-dative shift position or a regular to-position.

(23) a. Who did he give the creeps to __ last night?

b. *Who did he give the creeps last night to __ ?

(Bruening 2010a:299, (35))

(24) a. The man that he gave the creeps to last night is over there.

b. *The man that he gave the creeps last night is over there.

(Bruening 2010a:299, (36))

Extractability itself suggests that the movement takes place from an A-position, as Bruening argues, given that $\overline{\mathrm{A}}$-dislocated elements (including shifted heavy XPs) do not allow extraction in general.

(25) a. I think that, to a person like him, you should never give anything.

b. *Who do you think that, to $t$, you should never give anything?

(Bruening 2010a:299, (38))

(26) a. I gave some money on Saturday to every boy who had helped me clean the yard.

b. *Who did you give some money on Saturday to?

(Bruening 2010a:299, (39)) 
In this context, consider Bruening's (2010a:sec. 5) discussion of WCO and variable binding, which he presents as a consequence of his R-dative shift proposal. He observes that wh-extraction of the complement of to in idiomatic and nonalternating-verb constructions induces WCO violations. $^{7}$

(27) a. *Who ${ }_{1}$ did you spare his ${ }_{1}$ ordeal to?

b. $* \mathrm{Who}_{1}$ did the boss deny his 1 pay to ?

(Bruening 2010a:300, (41))

From these facts, Bruening concludes that hierarchical approaches to WCO fail to account for (27), given that (a) in its movement from an R-dative shift structure to the higher position the quantifier does not cross over the theme in the structure proposed in (5), and (b) the trace of who c-commands the pronoun. Instead, Bruening suggests that linear proposals regarding WCO deal better with these data, because the pronoun intervenes linearly between the wh-element and its trace. Additional considerations lead Bruening to adopt Ross's (1967) approach to the WCO condition in (28).

(28) The Crossover Condition

No NP mentioned in the structural index of a transformation may be reordered by that rule in such a way as to cross over a coreferential NP.

(Ross 1967:73, (4.30))

However, a clear alternative would be to maintain the structural proposal regarding WCO and to revise Bruening's derivation in (5). Indeed, if (27) corresponds to a regular to-construction

\footnotetext{
${ }^{7}$ In our opinion, characterizing deny-type verbs as nonalternating is an overstatement commonly found in the literature (see, e.g., Pinker 1989, Levin 1993, Krifka 2004). It is true that deny regularly appears in the DOC version; however, independently of the cases Bruening discusses, we have found many instances of to-constructions.

(i) a man who has repeatedly denied assistance to abused children (http://www.raelpress.org/news.php?item.182.1)

(ii) IDF soldiers denied medical treatment to several wounded activists who died shortly thereafter. (http://en.wikipedia.org/wiki/Gaza_flotilla_raid)

(iii) Governor Rick Scott denied the right to vote to hundreds of thousands, maybe as many as a million, Florida citizens. (http://www.huffingtonpost.com/2011/03/30/floridians-rick-scott-grifter_n_842597.html)

Similarly, there is another interpretation of deny where the direct object is necessarily animate.

(iv) He denied Jesus to that maid. (http://www.biblecenter.de/bibel/widerspruch/e-wds10.php)

(v) You denied him to the whole world. (http://www.smartparenting.com.ph/parentchat/index.php?action = profile; area $=$ showposts; $\mathrm{u}=25235$ )

The cases in (iv)-(v) are reminiscent of the Person Case Constraint (PCC)/Object Agreement Constraint (OAC) analyzed in Ormazabal and Romero 2007, where we discuss the relation of this constraint to animacy in a variety of languages including English (see also example (i) in footnote 5). In fact, the behavior of deny is similar to the behavior of the Spanish verb dar 'give', which in general situations requires a dative clitic. This clitic disappears just in those cases where the object is animate, as a sort of "repair strategy" to avoid the PCC/OAC effects (see Ormazabal and Romero 2007, Rezac 2010).
} 
and who proceeds from the PP-internal position, the quantifier crosses the theme in the object position and the effects derive from a standard WCO configuration.

This alternative becomes more obvious when we consider WCO together with variable binding. Given that WCO is conceived in (28) as a linear condition, Bruening must completely separate this constraint from the condition on variable binding, which he maintains is basically structural in nature. Despite this, he claims that variable binding also requires a linearity condition, in addition to the structural one. The result is a disjunctive definition of the condition governing variable binding.

(29) A quantifier $\mathrm{Q}$ can bind a pronoun $\mathrm{P}$ as a variable only if

a. Q takes scope over P (Q c-commands $\mathrm{P}$ ) and

b. Q precedes $\mathrm{P}$.

(Bruening 2010a:302, (48))

Despite being based on linearity, the precedence clause in (29b) cannot be reduced to the WCO constraint Bruening adopts in (28). It is motivated in Bruening's account by the fact that " $\mathrm{R}$ dative shift plus heavy shift also seems to destroy the possibility of variable binding, strongly for some speakers and more weakly for others"' (p. 302).

(30) a. Let's spare everyone ${ }_{1}$ his $_{1}$ upcoming ordeal.

b. ??Let's spare his ${ }_{1}$ upcoming ordeal to [every third prisoner with blond hair ${ }_{1}$.

(Bruening 2010a:302, (46))

(31) a. The boss denied every worker his $_{1}$ pay.

b. ??The boss denied his ${ }_{1}$ pay to [every illegal immigrant working for him] $]_{1}$.

(Bruening 2010a:302, (47))

The condition in (28) cannot account for the deviance of (30b) and (31b), "since the base position of the goal NP is to the right of the theme NP (and it c-commands the theme NP), and heavy shift simply moves it higher and further to the right in these examples"' (p. 302); hence, no linear crossing occurs. This forces Bruening to include the precedence clause (29b) in the condition on variable binding.

The result is a system that contains a WCO condition based on linear crossing plus a disjoint constraint on variable binding, with a structural clause based on c-command and a second, weaker condition based on linear precedence. In other words, the system requires three general conditions, of conceptually different natures, to account for what most probably constitutes a unified syntactic phenomenon. Paradoxically, the main effect of such an approach is that it makes the R-dative shift cases in (30b) and (31b) behave in exactly the same way as regular to-constructions like (32).

(32) ??I gave a copy of his grades to every boy $_{1}$.

(Bruening 2010a:302, (49b))

Clearly, the simplest way to achieve this unification is to recognize these cases as having the same basic structure. This simpler analysis does not seem to present any additional problem, 
as we have argued extensively. In fact, the standard to-analysis has the additional theoretical advantage that the precedence clause in (29b) can be dispensed with and the disjunction is eliminated from the constraint. This would reduce the complexity of the theoretical apparatus, given that R-dative shift constitutes the only motivation for the two linear conditions in the WCO constraint and in the complex definition of bound pronoun licensing. Once we eliminate the disjunction in the latter and go back to a c-command-based approach to WCO and variable binding, a unified analysis of all the Barss and Lasnik (1986) phenomena in simple structural terms can be pursued again, a desirable result.

\section{Broadening the Scope}

Thus far, we have demonstrated that if we play strictly by the rules imposed in Bruening's system, a regular to-construction analysis deals with all the empirical phenomena discussed by Bruening in a much simpler and theoretically more natural way than the R-dative shift proposal. Furthermore, we have shown that only a PP analysis is compatible with the structural facts regarding $w h$ movement and Barss and Lasnik's (1986) asymmetries. These results diminish Bruening's central claim that nonderivational polysemic approaches to dative alternations are superior-if not required by the system.

That established, our goal in this section is to broaden the scope of inquiry and extend its empirical domain. Our proposals here are somewhat less conclusive than in previous sections, but the new empirical material we present is robust and conclusive. It clearly shows that the contexts to which Bruening confines his explanation concerning pair-list readings and scope freezing are more complex than he envisages, and also extend to structures where no R-shifted datives or even idiomatic readings can be invoked. All this strongly suggests that Bruening's evidence concerning pair-list readings and scope freezing should be reanalyzed in radically different terms. In this context, our discussion of some of the theoretical consequences is an attempt to open new paths for further research and scientific discussion.

\subsection{Pair-List Readings}

An interesting fact that can be considered as potential evidence in favor of Bruening's position is the disappearance of the pair-list readings in idioms and deny-type verbs that he discusses at the end of section 2. Bruening observes a contrast between R-dative shift and "regular' toconstructions. In to-constructions, a pair-list reading is available when a $w h$-phrase is extracted from a to-PP over a universal quantifier in object position, (33). This reading disappears when the extracted element forms part of an idiom, (34a), or a nonalternating dative verb like deny, (34b).

(33) Let's make a list of who he assigned every request to. (pair-list OK) (Bruening 2010a:296, (24c))

(34) a. \#Let's make a list of who this lighting gives every kind of headache to. (*pair-list)

b. \#Let's make a list of who he denied every request to. (*pair-list)

(Bruening 2010a:297, (25b); 296, (24b)) 
According to Bruening, the minimal contrast in (33)-(34) shows that (34a-b) involve DOCs in disguise where the $w h$-phrase is structurally higher than the quantifier. However, the lack of pair-list readings in the case of idioms is more general and extends to less controversial cases where no DOC of any kind can be invoked. Compare the examples in (35)-(36) with Bruening's to-construction example in (33)-(34).

(35) a. Who will these photographs bring everything home to? (*pair-list)

b. (??)Among our students, who did we hand everything on a silver plate to? (*pairlist)

(36) a. (??)Whose mouth did the journalist put every word in? (*pair-list)

b. Which map did they put everything on? (*pair-list)

It is not easy to find idiomatic expressions that are flexible enough to satisfy all the structural requirements we need, and speakers find different degrees of degradation in some of the examples in (35)-(36) and similar cases independently of the intended readings. Abstracting away from judgment differences in (35)-(36), speakers feel reasonably comfortable with some of these structures. The two pairs of examples differ structurally. The examples in (35) have one slot for the theme and a second one for a prepositional goal or a locative element, and the idiom is formed by the verb together with a third element (e.g., home in (35a)). The examples in (36) are cases of fixed-goal or fixed-locative idioms. Unlike the fixed-theme idioms discussed by Bruening (e.g., (34)), all these examples share the properties of having some PP goal or locative and lacking DOC alternatives in general. Consequently, that the theme is structurally higher than the PP that the wh-phrase moves from in these cases does not seem to be under discussion; the structural conditions for the pair-list reading are thus fulfilled, exactly as in (33). However, while the regular PP construction in (33) allows the pair-list reading, speakers agree that this reading is not generally available in the idiomatic constructions in (35)-(36), which pair together with Bruening's fixedtheme idioms in (34). ${ }^{8}$

Moreover, our informants find some contrast in near-synonymous pairs like (37a-b), where the first sentence is a regular to-construction and the second is a parallel quasi-idiomatic expression. Although not completely ruling out (37b), the informants consistently find the pair-list reading more difficult with raise than with ask, which strongly confirms the general pattern discussed in this section.

(37) a. Let's make a list of who you asked every question to

b. (\#)Let's make a list of who you raised every question to

\footnotetext{
${ }^{8}$ We asked our informants about quite a few idioms of the types in (34) and, following Bruening's strategy, we asked them to check whether the pair-list reading was available when the sentences were embedded in a context like "Let's make a list of ...,', which makes this reading more salient. Speakers showed differences concerning particular examples in our sample, but they consistently disallowed pair-list readings in general in these contexts. One of our informants made an interesting comment, noting that pair-list readings become more available in some cases as the idiomatic construction is replaced by a more compositional interpretation of the sentence, in line with our suggestion in section 4.2 .
} 
In fact, as observed by an anonymous $L I$ reviewer, the problem extends to cases that clearly do not involve idiomatic expressions or nonalternating verbs, such as (38).

(38) I want you to list which corporations the revolution brought every problem to. (*pairlist)

In sum, interesting and mysterious as the behavior of idiomatic expressions with regard to pair-list readings may be, the lack of such readings, when analyzed in a broader context, does not seem to constitute evidence for Bruening's R-dative shift proposal in (5).

\subsection{Frozen Scope}

There are some facts suggesting that the explanation of the scope-freezing effects is also independent of structural conditions and has more to do with the referential content of the fixed elements in an idiomatic expression. Consider, for instance, the following Spanish minimal pair:

(39) a. Sara puso toda la carne en el congelador.

Sara put all the meat in the freezer

'Sara put all the meat in the freezer.'

b. Sara puso toda la carne en el asador.

Sara put all the meat in/on the barbecue

'Sara did her best.'

In a situation where Sara distributed all the meat in different freezers, (39a) is felicitous provided that the entire amount of meat ends up in one freezer or another. The question of whether that is possible in the idiom in (39b) is even difficult to formulate. The reason seems to us to be that la carne 'the meat' and el asador 'the barbecue' have no real referential content: there is no meat to distribute and there are no barbecues to put the meat on. It is not obvious to us how these observations could be unified with the scope interactions examined in this article, but the discussion suggests a different way to deal with the issue altogether. In fact, if we extend our arguments in section 4.1 to the scope-freezing facts, fixed-goal and fixed-locative idioms in Spanish seem to show the same scope restrictions attributed by Bruening to fixed-theme idioms in English.

(40) a. La empresa invierte todos sus recursos en un agujero sin fondo the company invests all its resources in a hole without bottom (*diferente) cada año. different each year

'The company wastes all its resources in (*different) profitless investments each year.'

b. La empresa invierte todos sus recursos en un proyecto renovador the company invests all its resources in a project innovative (diferente) cada año. different each year 'The company invests all its resources in a (different) innovative project each year.' 
As with the pair-list contexts discussed above, that the universal quantifier in object position is structurally higher than the complement of the locative preposition is not under discussion. However, as the impossibility of the modifier diferente 'different' in (40a) shows, a distributive reading of the universal quantifier over un agujero sin fondo (literally: 'a hole with no bottom') is impossible in the idiomatic expression, minimally contrasting with the structurally parallel, but fully referential, un proyecto renovador 'an innovative project' in (40b). Again, as observed in the previous examples, everything suggests that this contrast is related to the lack of referential content in the fixed part of the idiom.

In addition to these cases, an anonymous reviewer observes that the restriction in scope relations discussed in Bruening 2010a and in this section extends to other examples that do not involve idiomatic expressions. As the reviewer observes, (41a) and (41b) contrast minimally with respect to the universal quantifier's ability to take wide scope over the object in the to-PP.

(41) a. The revolution brought every kind of problem to a multinational corporation. (*every $>$ a)

b. The teacher brought every book to a different student. (every $>$ a)

The reviewer suggests that a relevant property that (41a) shares with Bruening's examples in (6) might be that these are cases where the caused-possession meaning does not involve a real transfer of possession, as opposed to cases like (41b), which allow a distributive reading. The reviewer proposes to link this distinction to the agentivity content of the subject.

The differences are subtle, and more work is needed to clarify many of the theoretical issues involved. But if the discussion in this section is on the right track, it offers the potential of a new way to make sense of the special scope restrictions. Given the exceptional character of idiomatic expressions, their scope restrictions might be linked to the referential properties of the elements that participate in these constructions.

\section{Concluding Remarks}

As shown by B\&N (2009) and RH\&L (2008), the existence of dative alternations in fixedtheme idiomatic expressions diminishes one of the classical arguments presented by proponents of polysemic approaches against derivational analyses. Recent work on the topic raises many other problems with the polysemic approach to dative alternations that seem to us more serious than the ones Bruening (2010a) tries to refute in the first place. In particular, mounting evidence supports the conclusion that the semantic differences between PP and dative constructions postulated to justify dedicated base structures reduce to lexical properties of the verbs and prepositions involved. Some of this research also shows, more generally, that so-called polysemy analyses run into unsolvable syntactic as well as semantic problems (see especially RH\&L 2008, B\&N 2009, Larson 2010, Ormazabal and Romero 2010, 2011). In addition, as we argue extensively in Ormazabal and Romero 2011, dative constructions require a derivational analysis involving the presence of an incorporated preposition, as in fact many languages show overtly. In the context 
of that broader theoretical discussion, the arguments presented here are just a small piece of evidence pointing in the same direction.

\section{References}

Barss, Andrew, and Howard Lasnik. 1986. A note on anaphora and double objects. Linguistic Inquiry 17: 347-354.

Bresnan, Joan. 1994. Locative inversion and Universal Grammar. Language 70:72-131.

Bresnan, Joan, and Jonni Kanerva. 1989. Locative inversion in Chicheŵa: A case study of factorization in grammar. Linguistic Inquiry 20:1-50.

Bresnan, Joan, and Tatiana Nikitina. 2009. The gradience of the dative alternation. In Reality exploration and discovery: Pattern interaction in language and life, ed. by Linda Ann Uyechi and Lian-Hee Wee, 161-184. Stanford, CA: CSLI Publications.

Bruening, Benjamin. 2001. QR obeys Superiority: Frozen scope and ACD. Linquistic Inquiry 32:233-273.

Bruening, Benjamin. 2010a. Double object constructions disguised as prepositional datives. Linguistic Inquirv 41:287-305.

Bruening, Benjamin. 2010b. Ditransitive asymmetries and a theory of idiom formation. Linguistic Inquiry 41:519-562.

Emonds, Joseph, and Rosemary Whitney. 2006. Thirty years of double object debates. In The Blackwell companion to syntax, vol. 2, ed. by Martin Everaert and Henk van Riemsdijk, 16-59. Oxford: Blackwell.

Green, Georgia M. 1974. Semantic and syntactic regularity. Bloomington: Indiana University Press.

Harley, Heidi. 2002. Possession and the double object construction. Yearbook of Linguistic Variation 2: 29-68.

Krifka, Manfred. 2004. Semantic and pragmatic conditions for the dative alternation. Korean Journal of English Language and Linguistics 4:1-32.

Larson, Richard. 1988. On the double object construction. Linguistic Inquiry 19:335-391.

Larson, Richard. 1990. Double objects revisited: Reply to Jackendoff. Linguistic Inquiry 21:589-632.

Larson, Richard. 2010. On Pylkkänen's semantics for low applicatives. Linquistic Inquirv 41:701-704.

Levin, Beth. 1993. English verb classes and alternations: A preliminary investigation. Chicago: University of Chicago Press.

Marantz, Alec. 1993. Implications of asymmetries in double object constructions. In Theoretical aspects of Bantu grammar, vol. 1, ed. by Sam A. Mchombo, 113-150. Stanford, CA: CSLI Publications.

Ormazabal, Javier, and Juan Romero. 2007. The Object Agreement Constraint. Natural Language and Linguistic Theory 25:315-347.

Ormazabal, Javier, and Juan Romero. 2010. The derivation of dative alternations. In Argument structure and syntactic relations: A cross-linguistic perspective, ed. by Maia Duguine, Susana Huidobro, and Nerea Madariaga, 203-232. Amsterdam: John Benjamins.

Ormazabal, Javier, and Juan Romero. 2011. Why P. Ms., HiTT, University of the Basque Country (UPV/ EHU) and University of Extremadura.

Pinker, Steven. 1989. Learnability and cognition: The acquisition of argument structure. Cambridge, MA: MIT Press.

Rappaport Hovav, Malka, and Beth Levin. 2008. The English dative alternation: The case for verb sensitivity. Journal of Linguistics 44:129-167.

Rezac, Milan. 2010. Phi features and the modular architecture of language. Dordrecht: Springer.

Ross, John R. 1967. Constraints on variables in syntax. Doctoral dissertation, MIT, Cambridge, MA.

Snyder, Kieran Margaret. 2003. The relationship between form and function in ditransitive constructions. Doctoral dissertation, University of Pennsylvania, Philadelphia. 
(Ormazabal)

University of the Basque Country (UPV/EHU)

Group of Theoretical Linguistics (HiTT)

Department of Linguistics and Basque Studies

Unibertsitateen ibilbidea 5

01006 Vitoria-Gasteiz.

Spain

javier.ormazabal@ehu.es

(Romero)

University of Extremadura

Group of Theoretical Linguistics (HiTT)

Department of Hispanic Philology and Linguistics

Avenida de la Universidad $s / n$

10003 Cáceres

Spain

juantxoromero@gmail.com 